\title{
Identification of Iatrogenic Complication of an Oncological Patient
}

\section{Pierpaolo Di Micco*}

UOC di Medicine, Fatebefratelli Hospital of Naples, Italy

\section{Image Article}

The image is a clear identification of iatrogenic complication of an oncological patient. The patient was selected for chemotherapy for a breast cancer. She placed a PICC to delivery chemotherapeutic drugs but there was a complication that is well documented in this image. The line into the X-ray is proximal terminal of the catheter that migrated through venous vessels into the right section of heart in particular.

The migration of the PICC into right ventricular induced in few days pulmonary embolism and hemodynamic collapse in the old patient that performed chemotherapy until the previous week (Figure 1).

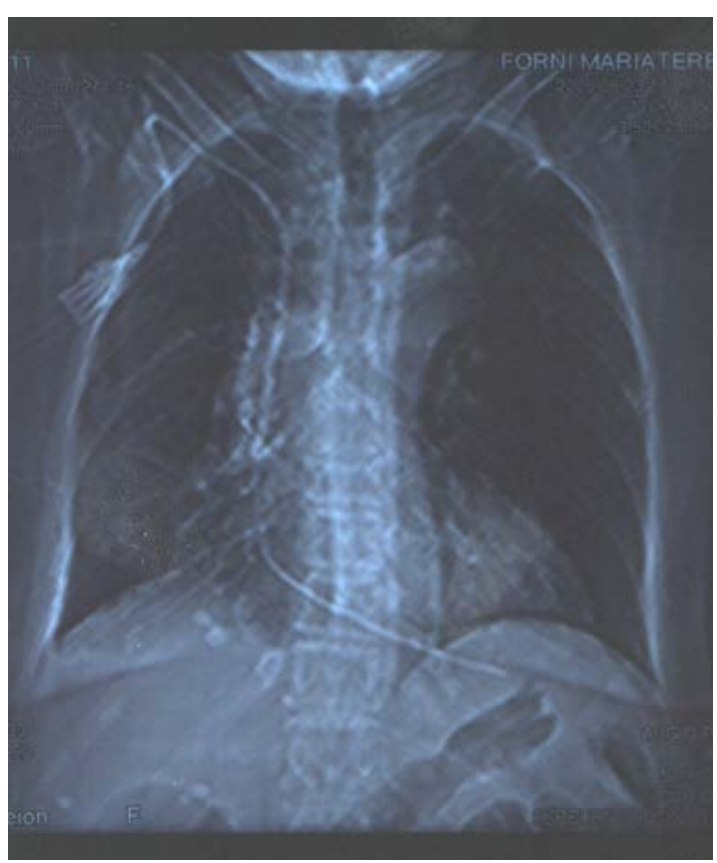

Figure 1: Identification of iatrogenic complication.

*Corresponding author: Di Micco P, UOC di Medicina, Fatebefratelli Hospital of Naples, Italy, Tel: 393398 078146; E-mail: pdimicco@libero.it

Received September 24, 2018; Accepted September 29, 2018; Published September 30, 2018

Citation: Micco PD (2018) Identification of latrogenic Complication of an Oncological Patient. J Blood Lymph 8: i104. doi: 10.4172/2165-7831.1000i104

Copyright: (c) 2018 Micco PD. This is an open-access article distributed under the terms of the Creative Commons Attribution License, which permits unrestricted use, distribution, and reproduction in any medium, provided the original author and source are credited. 